\title{
Congratulations to K. VijayRaghavan, Editorial Board Member of Structural Chemistry
}

\section{Istvan Hargittai}

Published online: 25 August 2013

(C) Springer Science+Business Media New York 2013

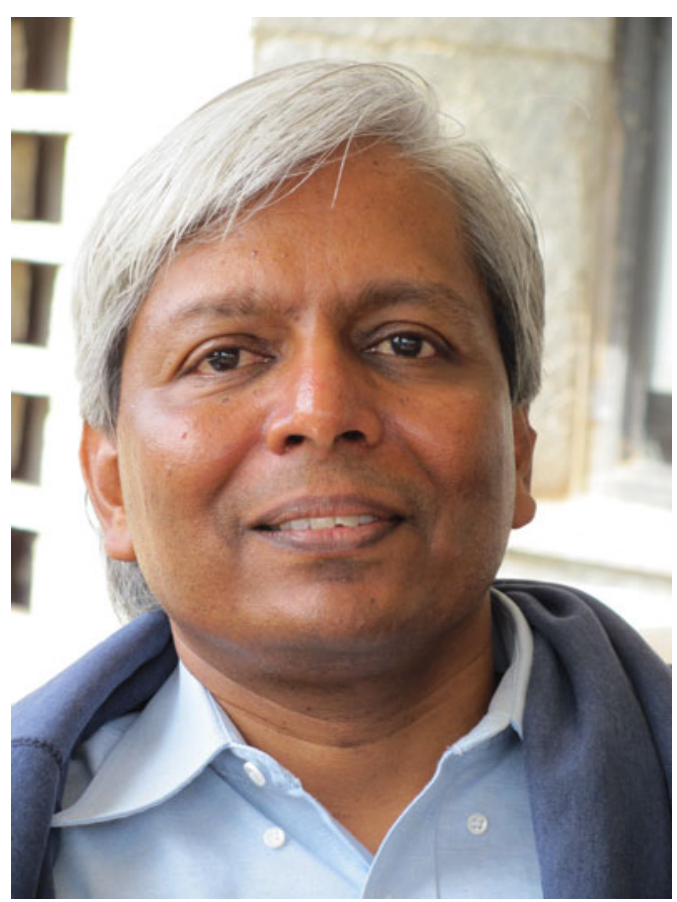

K. VijayRaghavan in September 2011 in Bangalore (photograph by Magdolna Hargittai). Vijay joined the Editorial Board of Structural Chemistry in the academic year 2011/12.
Krishnaswamy VijayRaghavan (Vijay to his friends), FRS, is Distinguished Professor and former Director of The National Centre for Biological Sciences, Bangalore, India. From January 28, 2013, he has been the Secretary of Department of Biotechnology, India.

Congratulations and best wishes to you, Vijay!
I. Hargittai $(\bowtie)$

Department of Inorganic and Analytical Chemistry, Budapest

University of Technology and Economics, PO Box 91,

Budapest 1521, Hungary

e-mail: istvan.hargittai@gmail.com 